\title{
FACTORS AFFECTING TBC FURNACE CYCLE LIFETIME: TEMPERATURE, ENVIRONMENT, STRUCTURE AND COMPOSITION
}

\author{
B. A. Pint ${ }^{1}$, J. A. Haynes ${ }^{1}$, M. J. Lance ${ }^{1}$, H. L. Aldridge, Jr. ${ }^{1}$, V. Viswanathan ${ }^{2}$, G. Dwivedi ${ }^{2}$ and S. Sampath ${ }^{2}$ \\ ${ }^{1}$ Oak Ridge National Laboratory, Materials Science and Technology Division, Oak Ridge, TN 37831-6156 USA \\ ${ }^{2}$ Center for Thermal Spray Research, Stony Brook University, Stony Brook, NY
}

Keywords: Thermal barrier coatings, HVOF, oxidation resistance, water vapor, composition effects

\begin{abstract}
Higher efficiency power generation turbines will benefit both natural gas-fired combined cycle units as well as coal gasification plants burning synthesis gas. Increasing efficiency is primarily linked to the turbine inlet temperature, where increases require improved materials such as a higher performance thermal barrier coating (TBC) with the durability needed by utility customers. An ongoing collaboration between Oak Ridge National Laboratory (ORNL) and the Center for Thermal Spray Research (CTSR) is combining expertise in processing and high temperature oxidation to understand relevant degradation mechanisms and identify promising concepts for further development. Screening of new TBC concepts in the laboratory typically involves furnace cycle testing (FCT) and this technique has been used to explore variables such as temperature, environment, roughness, structure and composition. For base load power generation duty, the traditional 1-h thermal cycle has been replaced in some experiments by 24- or 100 -h cycles, which has focused attention on the limitations of FCT. In order to link FCT results with observed long field TBC lifetimes in land-based turbines operating with $\sim 900^{\circ} \mathrm{C}$ metal temperatures, specimens were exposed in FCT at $900^{\circ} \mathrm{C}$ and $\mathrm{Al}$ loss after 5-20 kh exposures has been used to make initial lifetime predictions. Based on the observed FCT performance of flat coupons, the most recent work has explored cylindrical specimens.
\end{abstract}

\section{Introduction}

Fossil fuels continue to generate $\sim 70 \%$ of electricity in the U.S., where Americans consume $\sim 12 \mathrm{MWh} / \mathrm{yr} /$ person [1]. With the growing concern about emissions and possible regulations, the "least regret" strategy of generating less greenhouse gases in high efficiency systems [2] remains the most cost-effective method to reduce emissions from burning fossil fuels (compared to carbon capture and sequestration). With the current low cost of natural gas, new fossil fuel generation capacity is dominated by natural gas-fired combine cycle (NGCC) plants. Two full-size integrated gasification combined cycle (IGCC) plants burning coal-derived synthesis gas are operating in the U.S. (one in Indiana and the second one in Mississippi with $65 \%$ carbon capture [3]). For both NGCC and IGCC, increased turbine efficiency can help lower both emissions and the cost of electricity.

The pathway to higher turbine efficiency is typically by increasing the turbine inlet temperature. To achieve higher temperatures while maintaining the durability ( $>25 \mathrm{kh}$ between major overhauls) and reliability needed for the power generation industry, improved materials/coatings will likely be required. While ceramic hot section components may eventually be adopted [4], the current $\mathrm{Ni}$ base superalloy technology relies on film cooling and thermal barrier coatings (TBC) [5-11] to deal with turbine inlet temperatures that are $>1400^{\circ} \mathrm{C}$ in current gas turbine engines and will continue to increase in future designs. The traditional laboratory evaluation for new TBC concepts is furnace cycle testing (FCT) with thermal gradient testing, such as burner rigs, being used for promising TBC concepts before engine testing.

The current study focused on thermally-sprayed coatings used for large industrial gas turbines [12,13]. The FCT were mainly conducted in air with $10 \% \mathrm{H}_{2} \mathrm{O}$ as water vapor is present in all turbine exhaust gas. Some turbine concepts may contain even higher $\mathrm{H}_{2} \mathrm{O}$ contents depending on the fuel (synthesis gas or hydrogen) and the use of steam dilution [14-16]. Previous work showed that water vapor contents above $10 \%$ did not further affect performance [17-20] but numerous studies have shown that water vapor affects high temperature oxidation behavior [21-27] compared to testing in dry air. (Most FCT is performed in dry or laboratory air.) Also, FCT is commonly performed with 1-h cycles (i.e. $1 \mathrm{~h}$ furnace time followed by cooling). In this study, increased emphasis was placed on 100-h cycles because the IGCC duty cycle is expected to involve long periods when the gasifier is operational. The experiments examined several parameters to understand TBC performance and the limitations of FCT. Temperature was varied to study its effect on FCT lifetime and because actual metal temperatures will be much lower in order to achieve TBC lifetimes of $>25 \mathrm{kh}$. The FCT environment was modified to include $\mathrm{CO}_{2}$ and $\mathrm{SO}_{2}$. The superalloy substrate was varied as gas turbines use a range of both directionally solidified and single crystal superalloys. Also, several different processes and bond coating compositions were studied. Finally, different substrate shapes are beginning to be evaluated, both because of the limitations of flat disk coupons but also because burner rig testing is commonly performed on cylindrical specimens and properties such as residual stress in the thermally-grown alumina scale are usually only measured on flat specimens. If new TBC concepts are to be further developed, they will need to be evaluated on more complex geometry substrates.

\section{Experimental Procedure}

For fabricating coatings on superalloy disk specimens $(2 \mathrm{~mm}$ thick, $\sim 16 \mathrm{~mm}$ diameter with chamfered edges), the surface was grit blasted with alumina and then coated using standard commercialtype, air-plasma spray (APS), high velocity oxygen fuel (HVOF) and vacuum plasma spray (VPS) processes. In all cases, the coated substrates were then annealed in a vacuum of $10^{-4} \mathrm{~Pa}\left(10^{-6}\right.$ Torr $)$ for $4 \mathrm{~h}$ at $1080^{\circ} \mathrm{C}$. Except where noted the coatings are NiCoCrAlYHfSi $[6,28,29]$, Table 1 . Similar coatings were deposited on five different superalloy substrates with the compositions shown in Table 1 . The bond coatings were nominally $125 \mu \mathrm{m}$ thick. After annealing, a nominally $200 \mu \mathrm{m}$ thick $\mathrm{Y}_{2} \mathrm{O}_{3}$-stabilized $\mathrm{ZrO}_{2}$ (YSZ) top coating was deposited by APS. The top coating was either a standard deposition or a multilayer structure [30]. 
Groups of 3-5 similarly coated specimens were evaluated at each condition. For $1-\mathrm{h}$ cycles, the specimens were hung by a Pt-Rh wire in an automated cyclic rig and exposed for $1 \mathrm{~h}$ at temperature $\left(1075-1150^{\circ} \mathrm{C}\right)$ in air with $10 \pm 1 \mathrm{vol} . \% \mathrm{H}_{2} \mathrm{O}$ followed by cooling in laboratory air for $10 \mathrm{~min}$ for each cycle. For $24-\mathrm{h}$ cycles, the tests were conducted in laboratory air in a box furnace. For 100-h cycles, the specimens were placed in an alumina boat, heated to temperature over $\sim 4 \mathrm{~h}$ in an alumina tube with flowing argon, held for $100 \mathrm{~h}$ in flowing gas and then furnace cooled after the cycle in argon. Environments included (1) laboratory air, (2) air with $10 \pm 1 \%$ or $50 \pm 2 \%$ vol. $\% \mathrm{H}_{2} \mathrm{O}$, (3) buffered $90 \%\left(\mathrm{CO}_{2}-0.15 \% \mathrm{O}_{2}\right)+$ $10 \% \mathrm{H}_{2} \mathrm{O}$ and (4) $90 \%\left(\right.$ air $\left.+1000 \mathrm{ppm} \mathrm{SO}_{2}\right)+10 \pm 1 \% \mathrm{H}_{2} \mathrm{O}$. For the environments containing water vapor, the carrier gas was typically flowed at $500 \mathrm{ml} / \mathrm{min}$ with distilled water atomized into the gas stream above its condensation temperature. The injected water was measured to calibrate its concentration. Mass change was measured every 20 cycles using a Mettler-Toledo model XP205 balance but that data is not reported here. During the weighing, specimens were cooled to room temperature and visually examined.

Periodically during exposure, specimens were examined using a scanning electron microscope (SEM) equipped with an energy dispersive X-ray spectrometer (EDS). A Dilor XY800 Raman microprobe (Horiba Scientific, Edison, NJ) with an Innova 308c Ar+ laser (Coherent, Inc., Santa Clara, CA) operating at $5145 \AA$ with a power at the YSZ surface of $10 \mathrm{~mW}$ was used to measure the stress in the $\mathrm{Al}_{2} \mathrm{O}_{3}$ scale. Photo-stimulated luminescence piezospectroscopy (PSLS) stress maps were collected from the same $500 \times 670 \mu \mathrm{m}$ region, which was located by a fiducial marker cut into the YSZ top coating $[19,27,31,32]$. The intensity of the spectrum measured underneath the YSZ was $\sim 10,000$ times weaker than that typically measured from the scale on a bare bond coating. The surface was cleaned by compressed air to remove any scalecontaining debris before the measurement was made. The laser spot size and the mapping step size were both $10 \mu \mathrm{m}$ and the acquisition time for one spectrum was $0.1-0.5 \mathrm{~s}$. A total of 3468 spectra were collected for a map. Since the bond coat surface was not flat and the scale cracked, the stress state was not assumed to be biaxial and so hydrostatic stress (the average of the trace of the stress tensor) was determined by dividing the frequency shift of the R2 line from a zero stress reference (NIST standard reference material $676 \mathrm{~A}$ ) by $7.61 \mathrm{~cm}^{-1} / \mathrm{GPa}$ [33]. Owing to the large number of spectra collected no attempt was made to deconvolute multiple stress states and only a single stress (one set of R-lines) was fitted to each spectrum.

Coating failure was defined as $>20 \%$ loss of the YSZ layer but, in most cases, the entire top coating spalled in one piece at failure. After failure, the specimens were mounted in epoxy and then cut for metallographical polishing and examination by light microscopy and electron probe microanalysis (EPMA) using a JEOL model 8200.

\section{Results}

Effect of Temperature and Coating Process

Figure 1 shows the average lifetime of three coated alloy 247 specimens tested at each temperature. The error bars show one standard deviation. At $1100^{\circ} \mathrm{C}$, three different bond coatings were evaluated: VPS NiCoCrAlYHf (no $\mathrm{Si}$ addition) and NiCoCrAlYHfSi deposited by VPS and HVOF (two different sets of 3 specimens). The HVOF set with an average lifetime of 413 cycles had a multilayer YSZ top coating [30]. All of the other groups had a standard single YSZ layer. From these $1100^{\circ} \mathrm{C}$ experiments, there was no statistically significant difference among the lifetimes of these four variations. VPS NiCoCrAlYHf specimens were also evaluated at $1075^{\circ}$ and $1125^{\circ} \mathrm{C}$. VPS $\mathrm{NiCoCrAlYHfSi} \mathrm{specimens} \mathrm{were} \mathrm{cycled} \mathrm{at} 1125^{\circ}$ and $1150^{\circ} \mathrm{C}$. At the temperatures $\left(1100^{\circ}\right.$ and $\left.1125^{\circ} \mathrm{C}\right)$ where the coatings with and without $\mathrm{Si}$ were tested, these experiments did not show a significant difference in their average lifetimes. Comparing these two temperatures, the lifetimes also were not significantly different. However, the $1150{ }^{\circ} \mathrm{C}$ average lifetime was significantly lower than the other temperature results and the $1075^{\circ} \mathrm{C}$ results were significantly higher than the VPS NiCoCrAlYHf results at $1125^{\circ} \mathrm{C}$. Thus, the effect of temperature on TBC lifetime was as expected-lifetime decreased with increasing temperature.

Figure 2 shows representative light microscopy images of the failures among the specimens with standard YSZ top coatings. Typical of thermally sprayed coatings, failures occurred primarily in the YSZ near the bond coating. In these images, the bond coating appeared relatively flat. Figure 3 shows PSLS stress maps of the VPS NiCoCrAlYHfSi specimens after 100 1-h cycles at $1100^{\circ}-1150^{\circ} \mathrm{C}$. The brighter areas show higher stress and the darker areas lower stress. Similar to previous results, asperities in the bond coating resulted in local delamination of the scale and thus low stress regions. A clear result from Figure 3 is that the highest temperature exposure showed the largest drop in stress after 100 cycles and was $<100$ cycles from failure (average 187 cycles), whereas the other two specimens showed more regions of higher stress and had much higher average lifetimes 500 (at $1125^{\circ} \mathrm{C}$ ) and $567\left(\right.$ at $\left.1100^{\circ} \mathrm{C}\right)$ cycles.

\section{Effect of Coating Process}

Figure 4 shows another data set, this time using 24-h cycles and groups of three specimens where the results were more statistically significant. All of the $25 \mathrm{~mm}$ diameter René 80 specimens were sprayed with $\sim 150 \mu \mathrm{m} \mathrm{NiCoCrAlYHfSi}$ and the $\sim 300 \mu \mathrm{m}$ YSZ top coating was either porous ( $15 \%$ porosity) or dense (5\% porosity) YSZ. The APS bond coatings had the shorter lifetimes but the lifetime was higher with a porous YSZ top coating. In contrast, the HVOF lifetimes were higher, but the highest lifetime was achieved with the dense YSZ top coating. Currently, the stress levels in similar coatings from each group are being measured. The residual stress with the dense top coating appears higher (average

Table 1. Chemical compositions (atomic\% or ppma) determined by inductively coupled plasma analysis and combustion analysis.

\begin{tabular}{|c|c|c|c|c|c|c|c|c|c|c|}
\hline Material & $\mathrm{Ni}$ & $\mathrm{Cr}$ & $\mathrm{Al}$ & $\operatorname{Re}$ & $\mathrm{Co}$ & $\mathrm{W}$ & $\mathrm{Ta}$ & Mo & $\mathrm{Ti}$ & Other (ppma) \\
\hline $\mathrm{X} 4$ & 62.8 & 7.5 & 13.0 & 0.9 & 9.7 & 2.1 & 2.2 & 0.4 & 1.2 & $<3 \mathrm{Y}, 270 \mathrm{Hf}, 17 \mathrm{~S}$ \\
\hline $\mathrm{X} 4-1$ & 62.9 & 7.3 & 12.8 & 0.9 & 9.8 & 2.1 & 2.2 & 0.4 & 1.2 & $1-2 \mathrm{Y}, 2-3 \mathrm{La}, 340 \mathrm{Hf},<1 \mathrm{~S}$ \\
\hline 1483 & 60.8 & 13.6 & 7.3 & $<$ & 8.8 & 1.3 & 1.7 & 1.2 & 4.9 & $<1 \mathrm{~S}$ \\
\hline 247 & 60.3 & 9.7 & 12.6 & $<$ & 9.9 & 3.2 & 1.0 & 0.5 & 1.3 & $4700 \mathrm{Hf}, 8070 \mathrm{C},<3 \mathrm{~S}$ \\
\hline R80* & 58.6 & 15.4 & 6.4 & & 9.2 & 1.2 & & 2.4 & 6.0 & $400 \mathrm{Zr}, 8000 \mathrm{C}$ \\
\hline MCrAlYHfS & i 41.2 & 16.2 & 22.9 & & 18.4 & & & & & 3860Y,710Hf,6500Si,3S \\
\hline \multicolumn{4}{|c|}{$*$ nominal values } & $<$ le & an 0.0 & & & & & \\
\hline
\end{tabular}




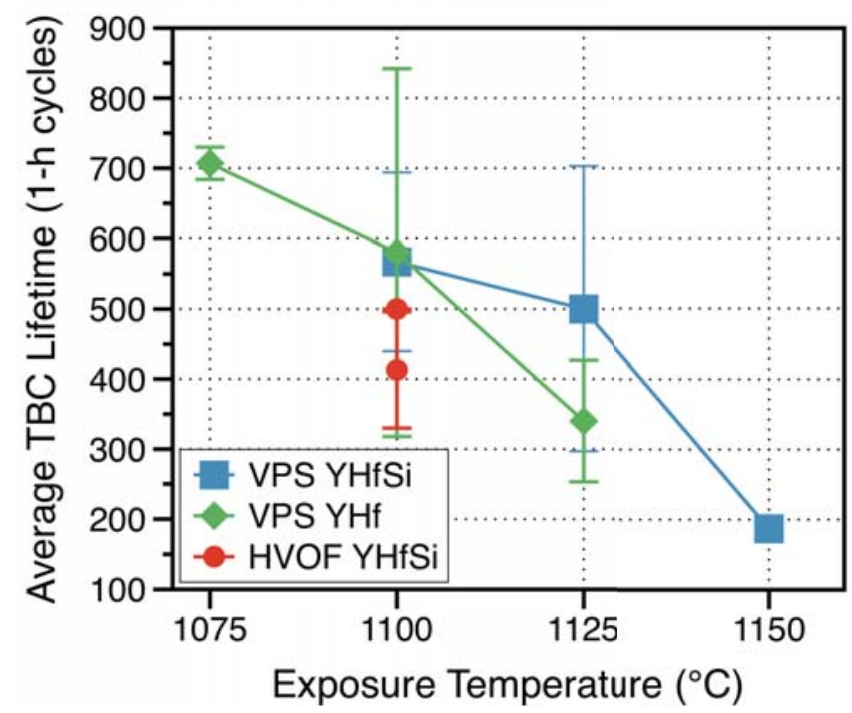

Figure 1. Summary of average lifetimes (total exposure time in 1h cycles) for APS YSZ-coated 247 with a VPS bond coating of NiCoCrAlYHf with and without a $\mathrm{Si}$ addition or HVOF $\mathrm{NiCoCrAlYHfSi}$. All of the experiments were conducted in air with $10 \% \mathrm{H}_{2} \mathrm{O}$.
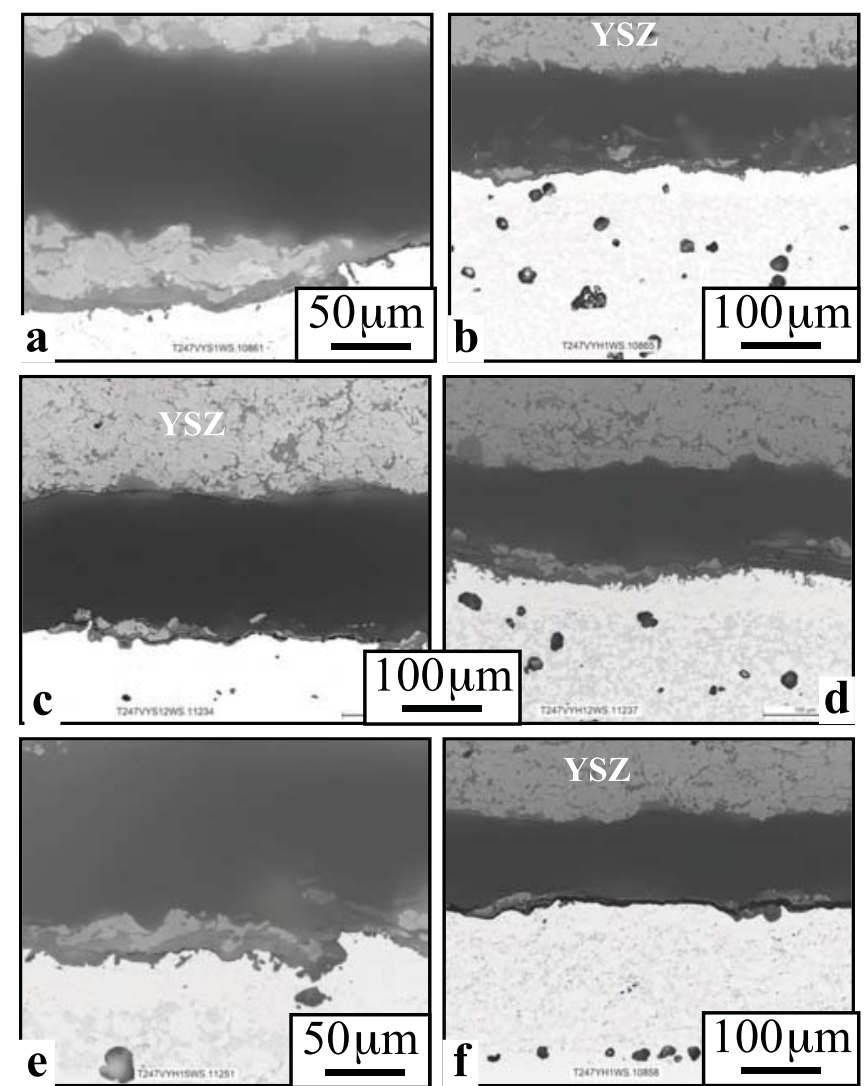

Figure 2. Light microscopy of polished cross-sections of failed coatings: VPS NiCoCrAlYHfSi after exposure at (a) $1100{ }^{\circ} \mathrm{C}$, (c) $1125^{\circ} \mathrm{C}$ and (e) $1150{ }^{\circ} \mathrm{C}$; VPS NiCoCrAlYHf after exposure at (b) $1100^{\circ} \mathrm{C}$ and (d) $1125^{\circ} \mathrm{C}$ and HVOF NiCoCrAlYHfSi after exposure at (f) $1100^{\circ} \mathrm{C}$. All had standard YSZ top coatings.
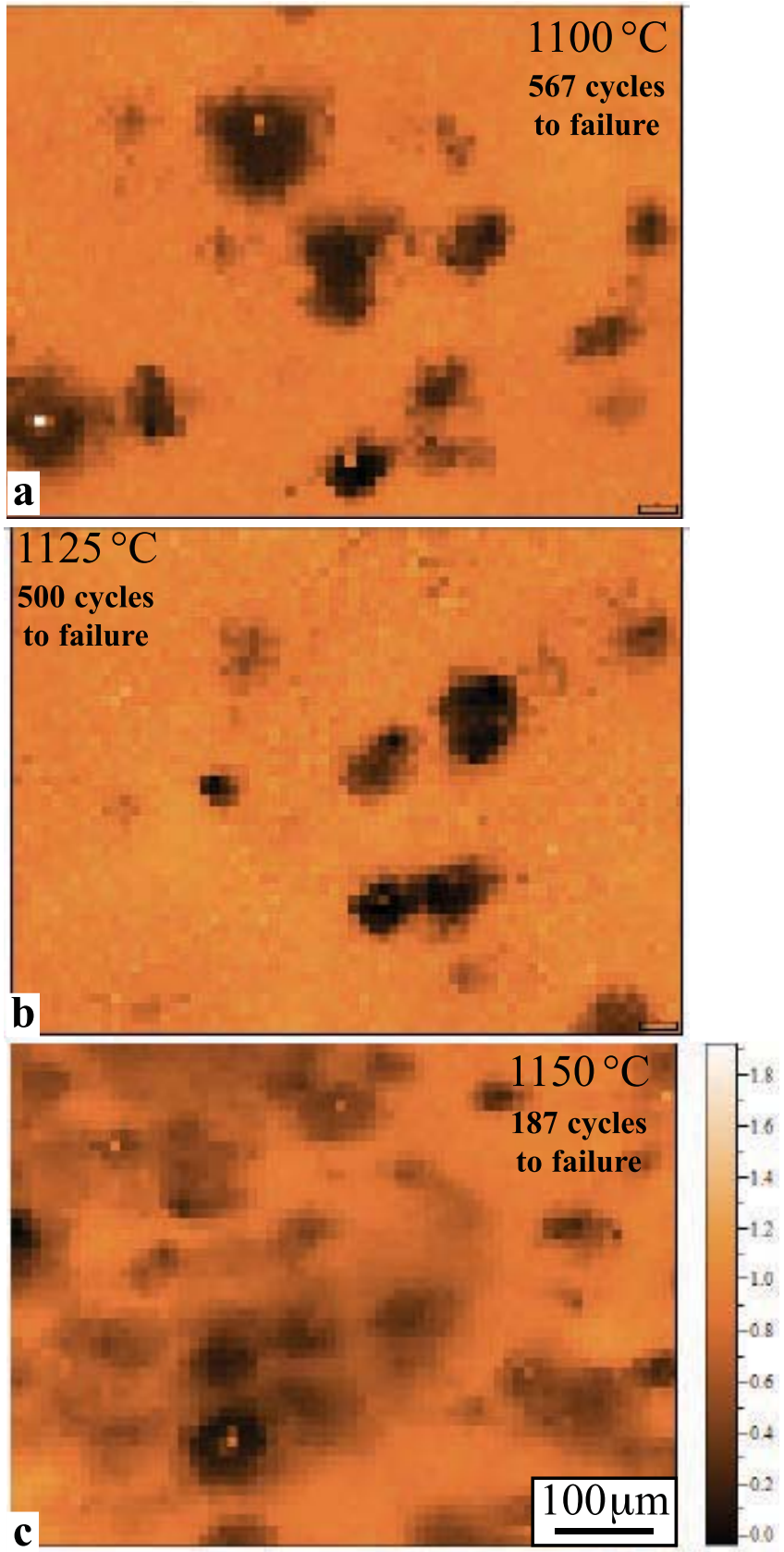

Figure 3. Stress maps after 100, 1-h cycles on the VPS $\mathrm{NiCoCrAlYHfSi}$ specimens exposed at (a) $1100^{\circ} \mathrm{C}$, (b) $1125^{\circ} \mathrm{C}$ and (c) $1150^{\circ} \mathrm{C}$. The measurements were made through the YSZ top coating and the stress levels are in units of GPa. The darker low-stress regions are likely alumina scale delaminations.

$\sim 1.7 \mathrm{GPa})$ than with the porous top coating (1.1-1.2 $\mathrm{GPa}$ average) after 4 cycles (96h).

Effect of Superalloy Substrate at $1100^{\circ} \mathrm{C}$

Figure 5 shows the 1-h and 100-h average lifetime for three batches of HVOF NiCoCrAlYHfSi bond coatings exposed at $1100^{\circ} \mathrm{C}$ in wet air. The results for the first batch on the $\mathrm{X} 4$ and $\mathrm{X} 4+\mathrm{RE}$ [34] substrates were presented earlier [18] and showed a 


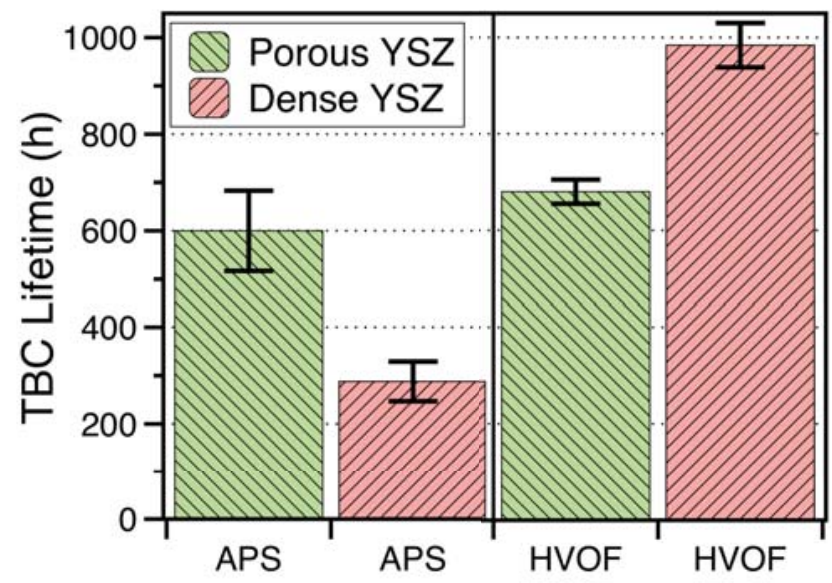

Figure 4. Average lifetime for 4 different process combinations on René 80 substrates exposed in $24-\mathrm{h}$ cycles at $1100{ }^{\circ} \mathrm{C}$ in laboratory air.

remarkable increase in coating lifetime when the cycle frequency was decreased from $1-\mathrm{h}$ to $100-\mathrm{h}$. The results from the second batch indicated a decrease in lifetime for the 1483 substrate compared to the X4 substrate with both 1-h and 100-h cycles. However, subsequent characterization showed that the average bond coating thickness in this batch was $\sim 90 \mu \mathrm{m}$ [32]. The relatively thin bond coating amplified the difference in $\mathrm{Al}$ content between the 1483 and X4 substrates, Table 1 . The result was that the low Al content 1483 substrate had significantly more interdiffusion, including large quantities of $\mathrm{Ti}$ in the bond coating at failure, especially in the 100-h cycle exposure [19]. For the third batch, which included alloy 247 , the average bond coating

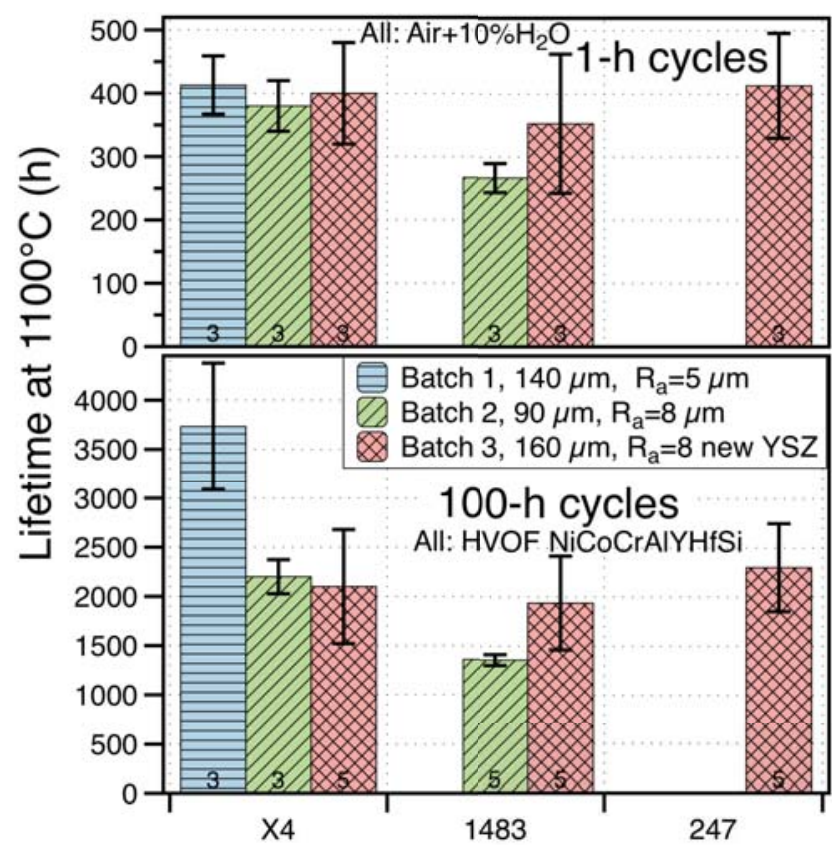

Figure 5. Average lifetime for 3 different superalloy substrates in $1 \mathrm{~h}\left(<500\right.$ cycle lifetimes) and $100 \mathrm{~h}$ cycles at $1100^{\circ} \mathrm{C}$ in wet air. All of the specimens have HVOF NiCoCrAlYHfSi bond coatings.
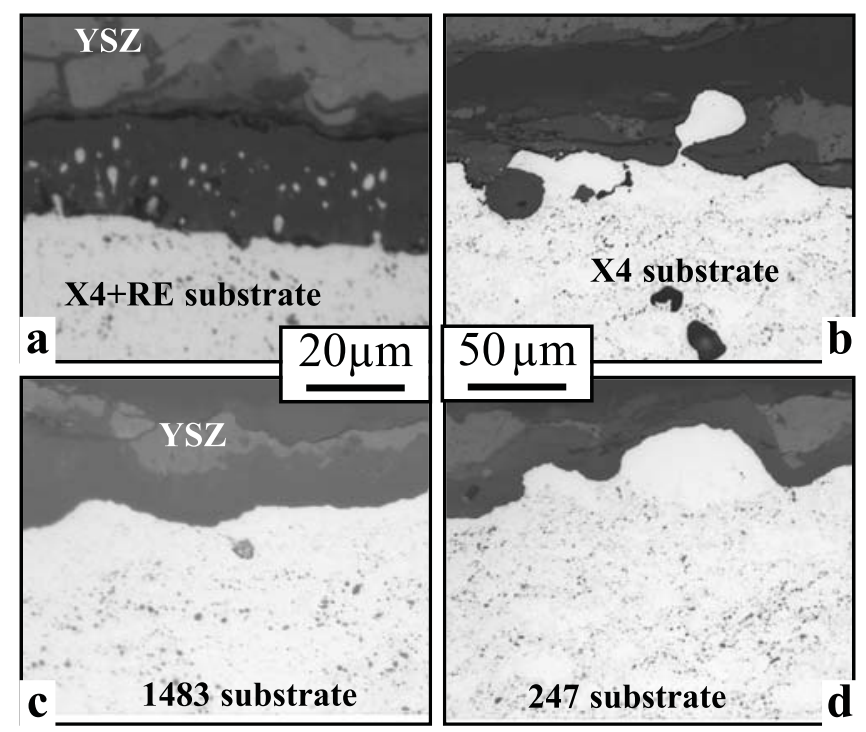

Figure 6. Light microscopy of polished cross-sections of failed HVOF NiCoCrAlYHfSi/APS-coated specimens exposed in air + $10 \% \mathrm{H}_{2} \mathrm{O}$ at $1100{ }^{\circ} \mathrm{C}$ (a) $\mathrm{X} 4+\mathrm{RE}$ substrate, 42,100 -h cycles, (b) $\mathrm{X} 4$ substrate 22,100 -h cycles, (c) 1483 substrate 24,100 -h cycles, and (d) 247 substrate $24,100-h$ cycles. (a) had $R_{a}=5 \mu \mathrm{m}$, while (bd) had $R_{a}=8 \mu \mathrm{m}$.

thickness was $\sim 160 \mu \mathrm{m}$. The results with both 1 -h [32] and $100-\mathrm{h}$ cycles was that the lifetimes for the three different superalloy substrates were statistically similar under these experimental conditions.

Figure 6 shows light microscopy of failures from batch 1 and batch 3 in 100-h cycles and illustrates one of the unusual aspects of this experiment. The batch 1 specimen with a 42 cycle lifetime exhibited "pegging" at the metal-scale interface (Figure 6a), resulting in a very adherent alumina scale and an extremely long lifetime [26]. In contrast. three of the specimens from batch 3 with different superalloy substrates are shown in Figures 6b-6d. No pegging was observed for any of the batch 3 specimens, which failed between 22 and 24 cycles in each case. For the batch 3 specimens, the oxide appeared similar in thickness with similar failure modes in each case.

Effect of Environment at $1100^{\circ} \mathrm{C}$

Figure 7 shows the effect of environment in 100-h cycles for mainly 1483 specimens from batch 2 . The X4 specimen from batch 2 (Figure 5) is shown for reference. Among the groups of 1483 specimens exposed with $\sim 90 \mu \mathrm{m}$ thick bond coatings, this set of experiments did not show much difference in lifetime for the wide range of exposure environments. Contrary to prior work on water vapor effects [27], these experiments did not show a negative effect of water vapor. The shortest lifetime was observed in laboratory air and the longest lifetime for the 1483 substrates was observed in air with $10 \% \mathrm{H}_{2} \mathrm{O}$. Similar average lifetimes near $1000 \mathrm{~h}$ of hot time were observed for air with $50 \% \mathrm{H}_{2} \mathrm{O}$, $\mathrm{CO}_{2}+10 \% \mathrm{H}_{2} \mathrm{O}$ and wet air with $0.1 \% \mathrm{SO}_{2}$. These specimens were characterized previously [20] and with these lifetimes at $1100^{\circ} \mathrm{C}$, the bond coatings were almost completely $\mathrm{Al}$ depleted. As noted previously [35], this can be considered a chemical failure [36] rather than a mechanical failure commonly observed in 1-h cycles. A chemical failure would explain why the environment had little effect on TBC lifetime, as the main failure mechanism was 


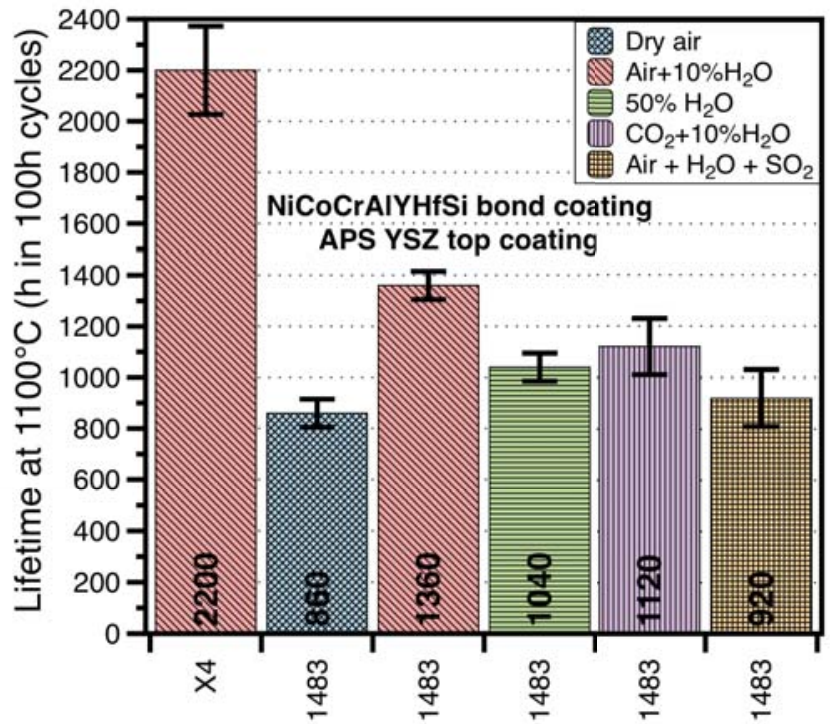

Figure 7. Average coating lifetimes (h in $100 \mathrm{~h}$ cycles to failure) for APS YSZ coated superalloy coupons with HVOF NiCoCrAlYHfSi type bond coatings $(\mathrm{Ra}=8 \mu \mathrm{m})$ exposed at 1100 ${ }^{\circ} \mathrm{C}$ in several different environments. Bars note a standard deviation for 3 specimens of X4 and 5 specimens of 1483 .

interdiffusion rather than an effect of, for example, water vapor on crack propagation [24]. In this batch of coatings, the interdiffusion was enhanced due to the low $\mathrm{Al}$ content of the 1483 substrate and the relatively thin $\sim 90 \mu \mathrm{m}$ bond coatings.

Lifetime modeling at $900^{\circ} \mathrm{C}$

Based on prior work $[35,36]$ a lifetime map could be constructed comparing results in 1-h and 100-h cycles, Figure 8. Echsler et al. [35] found that after 5,000 1-h cycles at $1050^{\circ} \mathrm{C}$, a chemical failure occurred for an APS sprayed TBC rather than a mechanical failure, Therefore, the regime from $1050^{\circ} \mathrm{C}$ to higher temperatures was concluded to be the mechanical failure regime. This was confirmed by the $1075^{\circ}-1150^{\circ} \mathrm{C}$ results in Figure 1. Below

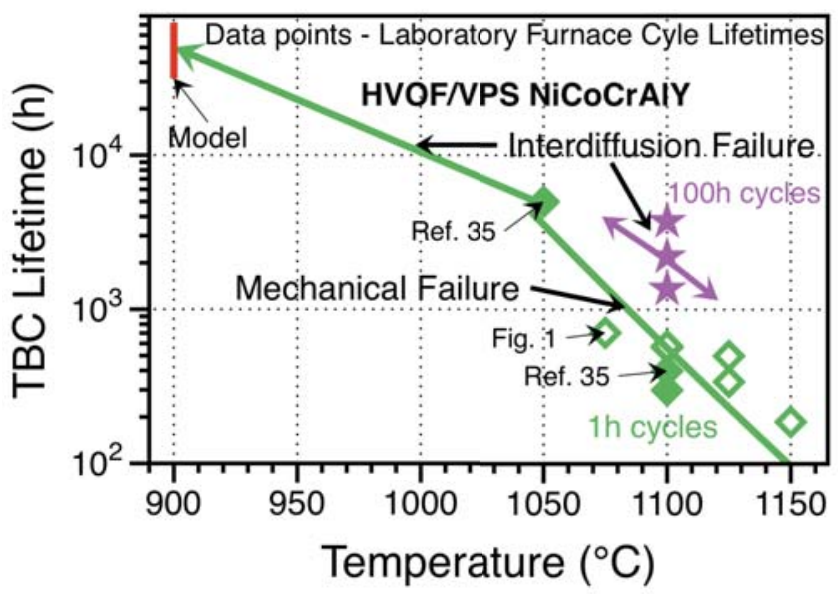

Figure 8. Summary of various FCT lifetimes at $1050-1100{ }^{\circ} \mathrm{C}$ and predicted lifetimes at $900{ }^{\circ} \mathrm{C}$ consistent with $\mathrm{TBC}$ overhaul times of $25-50 \mathrm{kh}$. $1050^{\circ} \mathrm{C}$, it was assumed that chemical or interdiffusion failure would dominate. The diffusion of $\mathrm{Al}$ from the bond coating will eventually deplete the bond coating resulting in a degradation of oxidation resistance and eventual coating failure. However, for 100 -h cycles, it appears that the chemical failure regime may extend to as high as $1100{ }^{\circ} \mathrm{C}$ because of the drop in the number of thermal cycles. Consider in Figure 5 that rather than the failure after $\sim 4001-\mathrm{h}$ cycles for several sets of coatings, the failure occurred after $\geq 20100$-h cycles.

In order to model interdiffusion at lower temperatures, interdiffusion data was generated by exposing specimens from batches $1-3$ at $900^{\circ} \mathrm{C}$ for $5000-20,000 \mathrm{~h}$ in wet air using $500-\mathrm{h}$ cycles. For example, Figure 9 shows the HVOF coating on X4 after $20,000 \mathrm{~h}$ at $900^{\circ} \mathrm{C}$. More complete characterization of these specimens will be presented elsewhere [37]. The specimens included three different versions of X4 with different levels of $\mathrm{Y}+\mathrm{La}$ and bond coatings with YHfSi (labeled YHS) and the same composition with only $\mathrm{Y}[18,26]$. The $\mathrm{Al}$ interdiffusion and $\beta$ phase depletion [35] were relatively modest at this temperature, even after $20 \mathrm{kh}$, Figure 9. Two different methods were used to predict lifetime at $900^{\circ} \mathrm{C}$. One was based on the percentage of $\beta$ phase depletion from the bond coatings, Figure 10a. Since the $\beta$ phase is rich in $\mathrm{Al}$, when it disappears, it indicates the coating is $\mathrm{Al}$ depleted. The most conservative estimate is for coating failure at $25 \%$ remaining $\beta$ phase resulting in lifetimes of $25-50 \mathrm{kh}$, Figure 10a. The most optimistic estimate is that the coating can survive to $100 \%$ depletion, resulting in lifetimes over $100 \mathrm{kh}$. These predictions suggest little difference in lifetime among the various combinations of superalloy and bond coating considered. Even the 1483 substrate with low Al showed similar lifetime as the $\mathrm{X} 4$ variants.

The other prediction method used the NASA COSIM interdiffusion model $[38,39]$, Figure $10 \mathrm{~b}$. For this model, the critical $\mathrm{Al}$ content for coating failure and interdiffusion rate are the key parameters that were varied. The diffusion rates could either be based on the measured profiles $\left(D_{\text {eff }}\right.$ in Figure 10b) or extrapolated from the Nesbitt (NASA) data (labeled extrapolate in Figure 10b). For this interdiffusion model, the lower Al content in 1483 (7.3at.\%) strongly affected the predicted lifetime. Critical Al contents of 9-13at.\% were used to define the failure criteria. The $\mathrm{Al}$ contents of $247(12.6 \%)$ and X4 (13\%) were higher than 1483

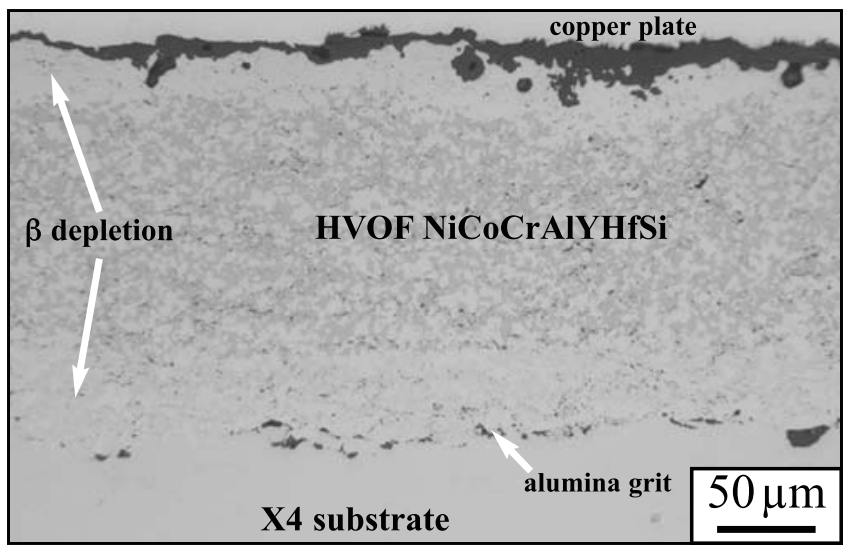

Figure 9. Light microscopy of polished cross-sections of HVOF NiCoCrAlYHfSi-coated $\mathrm{X} 4$ exposed in air $+10 \% \mathrm{H}_{2} \mathrm{O}$ at $900{ }^{\circ} \mathrm{C}$ for $20,000 \mathrm{~h}$. 

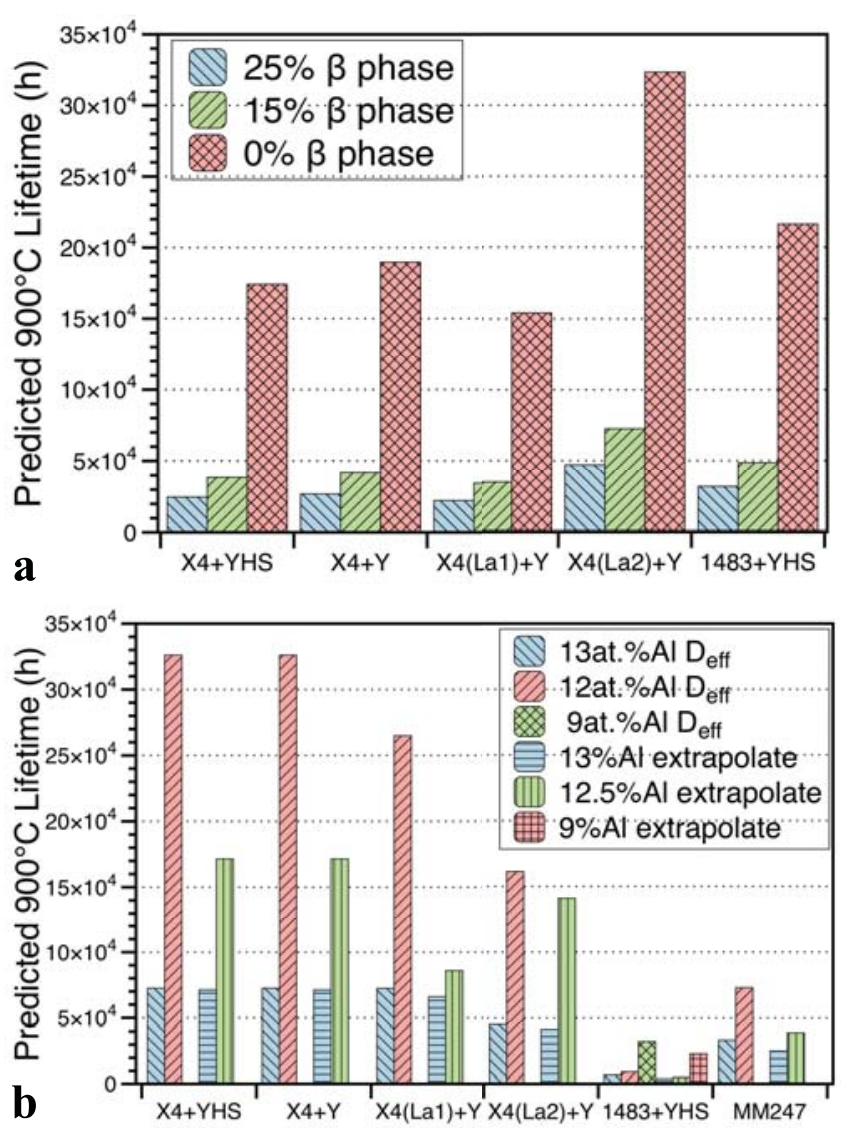

Figure 10. Lifetime modeling based on experimental data at $900^{\circ} \mathrm{C}$ for various substrates/HVOF bond coating combinations. (a) shows predicted lifetimes based on $\beta$-phase depletion with various levels of remaining $\beta$ in the bond coating; (b) shows predicted lifetimes based on the NASA COSIM model with various $\mathrm{Al}$ contents for the failure criteria.

so the predicted lifetimes are much higher, especially if the critical $\mathrm{Al}$ content was higher than the alloy $\mathrm{Al}$ content. The predictions by both methods are the same order of magnitude, however, it is obvious both methods are highly dependent on the failure criteria. Additional observations at $900^{\circ}-1100^{\circ} \mathrm{C}$ will assist in improving these lifetime predictions.

\section{Initial Results on Rod Specimens}

Figure 11 shows the first two alloy 247 rods ( $12.7 \mathrm{~mm}$ diameter), one sprayed with an APS NiCoCrAlYHfSi bond coating and the other using HVOF for the bond coating. The rods were cut by EDM into 4 rodlets each. The first segments of each were exposed in 100 -h cycles at $1100^{\circ}$ and $1150{ }^{\circ} \mathrm{C}$ in air with $10 \% \mathrm{H}_{2} \mathrm{O}$. Figure

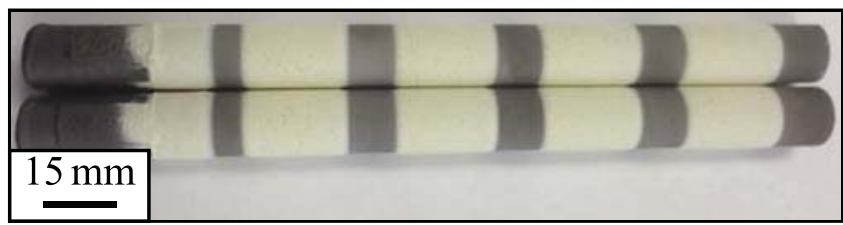

Figure 11. Coated alloy 247 rods wth APS top coating and APS and HVOF NiCoCrAlYHfSi bond coatings.

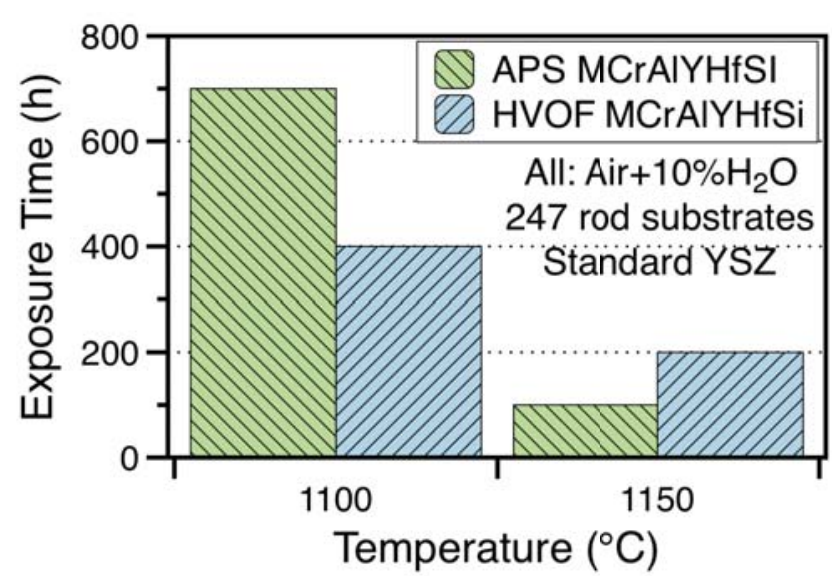

Figure 12. Summary of exposure times for the coated alloy 247 rods at $1100^{\circ}$ and $1150^{\circ} \mathrm{C}$ in 100 -h cycles.

12 shows that the lifetimes were much shorter than expected with the lifetimes at $1100^{\circ} \mathrm{C}$ lower than disk specimens under similar conditions, Figure 5. Additional work is needed to optimize the processing for this new type of specimen and understand the reason for the early failure. Initial evaluations suggest that a more compliant top coating is needed for rod specimens.

\section{Discussion}

The FCT results presented here examined the effect of a number of different parameters on TBC lifetime. The effect of temperature could be easily demonstrated, Figure 1 . The increased mismatch in thermal expansion coefficient between the thermally grown alumina scale and the MCrAlY bond coating increases with temperature [40] resulting in a decrease in coating lifetime. However, in the same set of experiments, changing from HVOF to VPS for depositing the NiCoCrAlYHfSi bond coating did not have a statistically significant effect on the coating lifetime, Figure 1. Normally it would be expected that VPS coatings should exhibit longer lifetimes. The 24-h FCT tests did show an effect of APS versus HVOF bond coatings and the YSZ density on TBC lifetime, Figure 4.

Figure 5 shows that initial attempts to increase the bond coating roughness between batches 1 and 2 did not result in the expected increase in coating lifetime. The higher roughness obtained by spraying coarser powder at the surface [27] may not have produced the optimal benefit. For the effect of substrate composition in Figure 5, it appeared that thicker bond coatings (batch 3, 160 $\mu \mathrm{m}$ ) could eliminate the effect of substrate on the FCT lifetime. The shorter lifetime for the 1483 substrate compared to X4 was obtained with a $\sim 90 \mu \mathrm{m}$ bond coating in batch 2 . Obviously placing a thicker layer of Al-rich coating should be beneficial. At lower temperatures where interdiffusion contributes to failure, the substrate effect should be apparent for alloys with different $\mathrm{Al}$ contents. For the $\beta$ depletion model in Figure 10a, there did not appear to be a strong effect of substrate on the coating lifetime. However, for the COSIM modeling in Figure 10b, the coated 1483 specimens did result in shorter lifetimes as expected. Because of the long lifetimes involved, it is not realistic to be able to verify the model results, however, by evaluating depletion at several temperatures, better model inputs will be determined. This will be 
the focus of future work to develop the model.

As discussed previously [18], changing the cycle frequency strongly affected the coating lifetime, Figure 5. The 1-h cycle is most relevant to the aero-engine duty cycle. For IGCC turbines, it is expected that when the gasifier is running the turbine will be running in a base load-type operation for long periods of time. Thus, 100-h cycles were adopted with the recognition that much longer lifetimes might result. As shown in Figure 5, significantly fewer thermal cycles with 100-h cycles did extend the TBC lifetime. Figure 7 shows that the 100-h cycles resulted in very little effect of the gas environment on the coating lifetime, suggesting that there was a change in the failure mechanism from a mechanical failure to a chemical failure, Figure 8 . This is especially true for the thinner $(\sim 90 \mu \mathrm{m})$ bond coatings on the 1483 substrates shown in Figure 7. The combination of the long lifetimes in the 100-h cycles and the possible switch in the failure mechanism with long cycles also suggested that testing to failure may not be the best strategy for future work. Shorter experiments at a range of temperatures will provide diffusion ( $\mathrm{Al}$ and $\beta$ depletion) data needed for the lifetime model. However, the long 100 -h cycle experiments also produced the interesting result of a very long lifetime on one set of coatings and the associated formation of metal pegs [26] at the coatings-scale interface, Figure 6a. The pegging feature has not been reproduced in subsequent coating batches but would likely be beneficial to form in all cases.

In addition to not being able to observe some parameter effects with FCT, another limitation is that without a temperature gradient, no benefit of switching to a lower thermal conductivity top coating would be expected in FCT results. Perhaps if more specimens were exposed, better statistics would yield more information from these experiments. The more specimens fabricated of one type means that fewer parameters can be evaluated under a finitelyfunded research project. In this case, relatively small groups (3-5 specimens) were evaluated in order to explore more variables.

One reason for moving to the rod specimens used in other studies $[35,41]$ is avoiding issues with oxidation of the superalloy substrate. This was particularly an issue for the 1483 substrate with its lower Al content and higher Ti content, Table 1 [19]. An alternative explanation for the similar lifetimes of the 1483 specimens in Figure 7 is that oxidation of the disk edges contributed to the failure. However, comparing Figures 5 and 12, the coating lifetimes were significantly shorter for the coated alloy 247 rods than the flat disks. The reason for this reduction needs to be explored. One possibility is sintering of the ceramic layer. The YSZ densification kinetics at $1100^{\circ} \mathrm{C}$ need to be explored. The processing solution being pursued now is depositing more porous YSZ as in Figure 4. Nevertheless, by coating more complex specimens, the effect of geometry on residual stress in the alumina scale can be evaluated and this is currently in progress. The majority of results on flat substrates may not be relevant to turbine hardware with concave and convex surfaces. Rod specimens also provide a transition to burner rig and more sophisticated (and more expensive) evaluations of higher performance TBC concepts.

As this is a broad topic, several aspects have not been pursued or the work is in progress. One parameter to be determined is the effect of water vapor on the scale growth rate at $900^{\circ}-1000^{\circ} \mathrm{C}$, more realistic metal temperatures for bond coatings than the accelerated temperatures $\left(1050^{\circ}-1150^{\circ} \mathrm{C}\right)$ needed to cause failure in FCT experiments. At $900^{\circ} \mathrm{C}$, there is a possibility of hot corrosion. However, for the IGCC application with carbon capture [3], it is expected that the gas treatment will remove all of the sulfur from the gas, otherwise the sorbent will be damaged. Thus, the possibility of hot corrosion (e.g. $\mathrm{Na}_{2} \mathrm{SO}_{4}$ attack) has not been considered in this study. Obviously the model is at a preliminary stage. The path forward appears to be less focused on failure times in FCT testing and more attention to quantifying interdiffusion at lower temperatures to generate relevant model inputs and determine activation energies so that the $900^{\circ}-1050^{\circ} \mathrm{C}$ range can be modeled, Figure 8 . In general, one limitation of the ORNLCTSR team is that there is little opportunity to compare our findings and model outputs to field data for validation of the results.

\section{Summary}

Furnace cycle testing has been used to explore several different variables for sprayed TBC specimens with the goal of optimizing both the bond coating and top coating performance for commercial land based gas turbine applications. In a number of cases the furnace cycle testing results were frustrating where changes in composition or processing led to no statistically significant effect in the FCT results. However, the FCT results with different superalloy substrates did illustrate that for relatively thick bond coatings, the substrate effects can be minimized. Also, the 100-h cycle results led to a greater appreciation of more relevant interdiffusion failure mechanisms, which is now the basis for the modeling work. Future work will focus on the fabrication and testing of rod specimens with more compliant top coatings as ORNL and CTSR continue to collaborate on this complex subject.

\section{Acknowledgements}

The authors would like to thank Ken Murphy at Howmet, A. Kulkarni at Siemens and J. Nesbitt at NASA Glenn for their assistance. At ORNL, the authors are grateful to the technical support of G. Garner, T. Lowe, M. Stephens and T. Jordan. This research was sponsored by the U.S. Department of Energy, Office of Coal and Power R\&D, Office of Fossil Energy, (R. Dennis program manager).

\section{References}

1. P. Denholm and R. M. Margolis, "Land-use requirements and the per-capita solar footprint for photovoltaic generation in the United States," Energy Policy, 36, (2008), 3531-3543.

2. I. R. Summerfield, S. H. Goldthorpe and C. J. Bower, "Combating Global Warming-Reducing $\mathrm{CO}_{2}$ Emissions from Coal-Fired Power Plant," Proceedings of the Institute of Mechanical Engineering A-Journal of Power and Energy, 207 (A2), (1993), 81-88.

\section{3. www.mississippipower.com/kemper/Facts.asp}

4. R. Naslain, "Design, preparation and properties of non-oxide CMCs for application in engines and nuclear reactors: an overview," Composites Sci. Technol., 64(2), (2004), 155-170.

5. A. Bennett, "Properties of Thermal Barrier Coatings," Materials Science and Technology, 2, (1986), 257-261.

6. J. T. DeMasi-Marcin and D. K. Gupta, "Protective coatings in the gas turbine engine," Surface and Coatings Technology, 68-69, (1994), 1-9.

7. W. A. Nelson and R. M. Orenstein, "TBC Experience in Land-Based Gas Turbines," Journal of Thermal Spray Technology, 
6(2), (1997), 176-180.

8. G. W. Goward, "Progress in Coatings for Gas Turbine Airfoils," Surface Coatings Technology, 108-109, (1998), 73-79.

9. B. A. Pint, I. G. Wright, W. Y. Lee, Y. Zhang, K. Prüßner and K. B. Alexander, "Substrate and Bond Coat Compositions: Factors Affecting Alumina Scale Adhesion," Materials Science and Engineering, A245, (1998), 201-211.

10. J. R. Nicholls, "Advances in Coating Design for HighPerformance Gas Turbines," MRS Bulletin, 28, (2003), 659-670.

11. B. Gleeson, "Thermal Barrier Coatings for Aeroengine Applications," Journal Propulsion \& Power, 22, (2006), 375-383.

12. J. Stringer, "Coatings in the electricity supply industry: past, present, and opportunities for the future," Surface and Coatings Technology, 108-109, (1998), 1-9.

13. Y. Itoh, M. Saitoh and M. Tamura, "Characteristics of MCrAlY Coatings Sprayed by High Velocity Oxygen-Fuel Spraying System," Journal of Engineering for Gas Turbines \& Power, 122, (2000), 43-49.

14. I. G. Wright and T. B. Gibbons, "Recent developments in gas turbine materials and technology and their implications for syngas firing," International Journal of Hydrogen Energy, 32, (2007), 3610-3621.

15. P. Chiesa, G. Lozza and L. Mazzocchi, "Using Hydrogen as Gas Turbine Fuel," Journal of Engineering for Gas Turbines \& Power, 127, (2005), 73-80.

16. L. A. Ruth, "Advanced clean coal technology in the USA," Materials at High Temperature, 20, (2003), 7-14.

17. B. A. Pint, G. W. Garner, T. M. Lowe, J. A. Haynes and Y. Zhang, "Effect of increased water vapor levels on TBC lifetime with Pt-containing bond coatings," Surface and Coatings Technology, 206, (2011) 1566-1570.

18. B. A. Pint, J. A. Haynes, K. A. Unocic and Y. Zhang, "The Effect of Water Vapor and Superalloy Composition on Thermal Barrier Coating Lifetime," Superalloys 2012, ed. E. Huron et al., (Warrendale, PA: TMS, 2012), 723-732.

19. M. J. Lance, K. A. Unocic, J. A. Haynes and B. A. Pint, "The Effect of Cycle Frequency, $\mathrm{H}_{2} \mathrm{O}$ and $\mathrm{CO}_{2}$ on TBC Lifetime with NiCoCrAlYHfSi Bond Coatings," Surface and Coatings Technology, 260, (2014) 107-112.

20. B. A. Pint, K. A. Unocic and J. A. Haynes, "The Effect of Environment on TBC Lifetime," Journal of Engineering for Gas Turbines \& Power, 138 (8), (2016), 082102.

21. C. Leyens, K. Fritscher, R. Gehrling, M. Peters and W. A. Kaysser, "Oxide Scale Formation on an MCrAlY Coating in Various $\mathrm{H}_{2}-\mathrm{H}_{2} \mathrm{O}$ Atmospheres," Surface and Coatings Technology, 82, (1996), 133-144.

22. R. Janakiraman, G. H. Meier and F. S. Pettit, "The Effect of Water Vapor on the Oxidation of Alloys that Developed Alumina Scales for Protection," Metallurgical and Materials Transactions, 30A, (1999), 2905-2913.

23. K. Onal, M. C. Maris-Sida, G. H. Meier and F. S. Pettit, "Water Vapor Effects on the Cyclic Oxidation Resistance of Alumina-Forming Alloys," Materials at High Temperature, 20, (2003), 327-337.

24. J. L. Smialek, "Enigmatic Moisture Effects on $\mathrm{Al}_{2} \mathrm{O}_{3}$ Scale \& TBC Adhesion," Mater. Sci. Forum, 595-598, (2008), 191-198.

25. V. Déneux, Y. Cadoret, S. Hervier, and D. Monceau, "Effect of Water Vapor on the Spallation of Thermal Barrier Coating Systems During Laboratory Cyclic Oxidation Testing," Oxidation of Metals, 73, (2010), 83-93.

26. J. A. Haynes, K. A. Unocic and B. A. Pint, "Effect of Water Vapor on the $1100^{\circ} \mathrm{C}$ Oxidation Behavior of Plasma-Sprayed TBCs with HVOF NiCoCrAlX Bond Coats," Surface and Coatings Technology, 215, (2013), 39-45.

27. J. A. Haynes, K.A. Unocic, M.J. Lance and B.A. Pint, "Impact of Superalloy Composition, Bond Coat Roughness and Water Vapor on TBCs with HVOF NiCoCrAlYHfSi Bond Coatings," Surface and Coatings Technology, 237, (2013), 65-70.

28. D. K. Gupta and D. S. Duvall, "A Silicon and Hafnium Modified Plasma Sprayed MCrAlY Coating for Single Crystal Superalloys," Superalloys 1984, ed. M. Gell, et al. (Warrendale, PA: TMS, 1984), 711-720.

29. K. A. Unocic and B. A. Pint, "Characterization of the Alumina Scale Formed on a Commercial MCrAlYHfSi Coating," Surface and Coatings Technology, 205, (2010), 1178-1182.

30. V. Viswanathan, G. Dwivedi and S. Sampath, "Engineered Multilayer Thermal Barrier Coatings for Enhanced Durability and Functional Performance," Journal of the American Ceramic Society, 97, (2014), 2770-2778.

31. M. J. Lance, K. A. Unocic, J. A. Haynes and B. A. Pint, "Effect of Water Vapor on Thermally Grown Alumina Scales on Simple and Pt-modified Aluminide Coatings," Surface and Coatings Technology, 237, (2013), 2-7.

32. M. J. Lance, K. A. Unocic, J .A. Haynes and B. A. Pint, “APS TBC Performance on Directionally-Solidified Superalloy Substrates with HVOF NiCoCrAlYHfSi Bond Coatings," Surface and Coatings Technology, 284, (2015), 9-13.

33. Q. Ma, D. R. Clarke, "Stress Measurement in Single-Crystal and Polycrystalline Ceramics Using their Optical Fluorescence," Journal of the American Ceramic Society, 77, (1994), 298-302.

34. K. Harris and J. B. Wahl, "Improved Single Crystal Superalloys. CMSX-4®(SLS)[La+Y] and CMSX-486®," Superalloys 2004, ed. K. A. Green, T. M. Pollock, H. Harada, T. E. Howson, R. C. Reed, J. Schirra and S. Walston (Warrendale, PA: TMS, 2004), 45-52.

35. H. Echsler, D. Renusch and M. Schütze, "Bond coat oxidation and its significance for life expectancy of thermal barrier coating systems," Materials Science and Technology, 20, (2004), 307-318.

36. D. Renusch, M. Schorr and M. Schütze, "The role that bond coat depletion of $\mathrm{Al}$ has on the lifetime of APS-TBC under oxidizing conditions," Materials Corrosion, 59, (2008), 547-555.

37. H. L. Aldridge, Jr. and B. A. Pint, unpublished research 2015.

38. J. A. Nesbitt, "COSIM-A finite-difference computer model to predict ternary concentration profiles associated with oxidation and interdiffusion of overlay-coated substrates," in Lifetime Modelling of High Temperature Corrosion Processes, M. Schütze, W. J. Quadakkers, J. R. Nicholls eds, (London, UK: Maney, 2001), 359-378

39. J. A. Nesbitt and R. W. Heckel, "Modeling Degradation and Failure of NiCrAl Overlay Coatings," Thin Solid Films, 119, (1984), 281-290.

40. J. A. Haynes, B. A. Pint, W. D. Porter and I. G. Wright, "Comparison of Thermal Expansion and Oxidation Behavior of Various High-Temperature Coating Materials and Superalloys," Materials at High Temperature, 21, (2004), 87-94.

41. D. Naumenko, V. Shemet, L. Singheiser and W. J. Quadakkers, "Failure mechanisms of thermal barrier coatings on MCrAlY-type bondcoats associated with formation of thermally grown oxide," J. of Materials Science, 44, (2009), 1687-1703. 